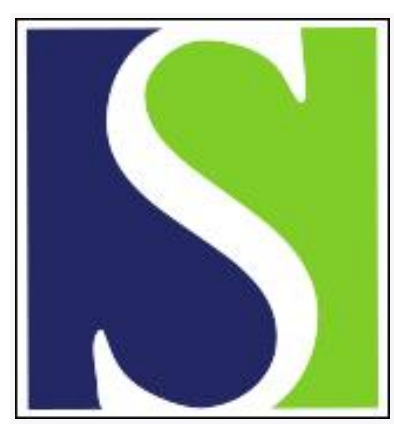

Scand J Work Environ Health 1999;25(6):491-497

https://doi.org/10.5271/sjweh.471

Issue date: Dec 1999

Occupational cancer epidemiology in the coming decades

by Blair A, Rothman N, Hoar Zahm S

Key terms: cohort; cross-sectional study; gene-exposure interaction; method; minority; nested case-control design; occupational cancer epidemiology; population-based case-control design; prospective design; woman

This article in PubMed: www.ncbi.nlm.nih.gov/pubmed/10884144

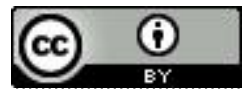




\title{
Occupational cancer epidemiology in the coming decades
}

\author{
by Aaron Blair, PhD, Nathaniel Rothman, MD' Shelia Hoar Zahm, ScD
}

\begin{abstract}
Blair A, Rothman N, Hoar Zahm S. Occupational cancer epidemiology in the coming decades. Scand J Work Environ Health 1999;25(6 special issue):491-497.

Occupational studies have identified many of the established chemical carcinogens. Studies in the next millennium will be needed to identify the hazardous agents in occupations known to have high cancer rates, to assess human risks from animal carcinogens that have not been well evaluated epidemiologically, to provide information on women and minorities, to evaluate interactions with genetic factors and other risk factors, to contribute to our understanding of risks from the spread of chemicals from the workplace to the general environment, and to identify mechanisms of cancer. The traditional retrospective cohort design will be insufficient to meet these needs. Population-based case-control, nested case-control, prospective cohorts, and cross-sectional designs will assume more important roles because of the need to collect information on nonoccupational risk factors and biological tissues. Improvement in the assessment of quantitative exposures is needed for the efficient evaluation of interactions between occupational exposures, genetic factors, and nonoccupational exposures.
\end{abstract}

Key terms cohort, gene-exposure interactions, methods, minorities, nested case-control, prospective designs, women.

Occupational studies have a long and productive history in identifying causes of cancer. Many chemicals classified as carcinogens by the International Agency for Research on Cancer were first evaluated in the workplace (1). The workplace has served as a natural laboratory and workers as sentinels for the general population in the identification of environmental carcinogens because exposures are typically of greater intensity, longer term, and more identifiable than in other environments. The workplace, because of its intense and readily documented exposures, has also provided much of what we know regarding the mechanisms of action of environmental carcinogens. Despite this long and successful history, there is a perception among many scientists, public health officials, and policy makers that the scientific and public health importance of occupational investigations on cancer has diminished. This perception partially stems from the belief that most major occupational carcinogens have already been identified and from the current enthusiasm for the study of genetic factors in cancer etiology. A focus on genetic factors does appear to provide the opportunity to enhance our understanding of the carcinogenic process. With finite resources it is appropriate to evaluate how important a role any area, including occupation- al studies, should play in the future of cancer epidemiology.

There are several reasons for the continued evaluation of cancer in the workplace. Investigations of occupational exposures remain useful for (i) identifying and clarifying new causes of cancer (candidate substances are those which are positive in animal bioassays or suggestive in epidemiologic studies, but for which the epidemiologic data are inconclusive, and new chemicals which enter the workplace), (ii) providing information on occupational risks among poorly studied subgroups (eg, women, minorities, and workers in developing countries or small businesses), (iii) providing critical information on the potential cancer risks associated with the spread of exposures from the workplace to the general environment, including the home, (iv) evaluating interaction and effect modification among occupational exposures, nonoccupational factors, and genes, and (v) providing a safe work environment.

Exposure to occupational carcinogens has important implications for both the worker and public health. In their comprehensive review, Doll \& Peto (2) concluded that tobacco accounted for about $30 \%$ of cancer deaths, diet about $35 \%$, and that other factors such as alcohol,

1 National Cancer Institute, Bethesda, Maryland, United States.

Reprint requests to: Dr A Blair, National Cancer Institute, Executive Plaza South, Room 8118, Bethesda, MD 20892, USA. 
food additives, reproductive and sexual behavior, pollution, industrial products, medicines, geophysical factors, infection, and occupation each contribute between $1 \%$ and $10 \%$. Because their estimate of attributable risk for occupation was $4 \%$, it is often perceived as unimportant.

We believe a more appropriate interpretation is that there are 2 major players in cancer etiology (ie, tobacco and diet) and that the contribution of each of the other categories of factors to the cancer burden is roughly similar (ie, from 1 to $10 \%$ ). It is of some importance that cancer risks from occupational exposures are not evenly distributed across the population. Among blue-collar workers, the attributable risk from occupational factors is estimated to be close to $25 \%$ (3). The occupational contribution also varies by site, being higher for lung and bladder cancers than for other cancers (4).

\section{Identification of new causes of cancer}

Although the pace of identification of new occupational causes of cancer has diminished since the heydays of the 1960 s, 1970s, and 1980s, there are several lines of evidence that suggest many factors remain to be uncovered. First, there is a long list of associations between cancer and individual occupations or industries for which the specific agents have not been identified (5). Some of these associations have been observed in multiple studies and for a considerable period of time (eg, bladder cancer among leather workers and lung cancer among plumbers and meat workers). Second, there is a large number of established animal carcinogens that have not been well investigated in humans $(6,7)$. Many of these substances (eg, pesticides and organic solvents) are widely used in industry and can be found in numerous consumer products, thereby creating considerable opportunity for human exposure. Although several insecticides, herbicides, and fungicides are positive in animal bioassays (7), other than arsenic compounds, no single pesticide is classified as a human carcinogen by the International Agency for Research on Cancer (IARC) (8). The IARC classification of limited evidence for several pesticides and for the general occupational category "spraying of insecticides" suggests, however, that these chemicals pose a risk to humans. The widespread use of pesticides in agriculture, on public grounds, in industry, and in and around homes creates considerable opportunity for human exposure $(9,10)$.

Organic solvents are another class of chemicals which are important to industry and can be found in many consumer products. Carcinogenic activity has been documented in bioassays for several solvents, yet only benzene is classified as a human carcinogen (7). Substantial occupational exposures, considerable opportunity for exposures to the general population, positive experimental findings, and suggestive epidemiologic results for a number of solvents document the need for further occupational studies of these and other potential human hazards.

\section{Women, minorities and workers in developing countries}

Most studies of occupational cancer have been conducted in developed countries and have mainly focused on white men employed in large firms $(11,12)$. Relatively few studies of occupational cancer have included women and minorities and even fewer have had sufficient numbers for meaningful analyses (12). There are several reasons why a reliance on studies of white men might present a distorted picture regarding the cancer burden from workplace exposures. Gender and ethnicity could influence how people approach their job, which could affect level and timing of exposure. Gender differences in body size, physiology, and hormones may also affect the ultimate impact of exposure to chemical carcinogens (13). There is some epidemiologic evidence to suggest that relative risks for cancer from similar exposures may differ among men and women. Several studies have observed a higher risk of lung cancer from smoking among women than among men $(14,15)$, even after standardizing for the amount and timing of smoking. In an occupational study, the risk of non-Hodgkins lymphoma and multiple myeloma from exposure to organic solvents during the maintenance and repair of aircraft appeared to be greater for women than for men (16). Occupational studies of cancer among women are needed because gynecologic cancers cannot be investigated in men and bioassays indicate that cancers of the reproductive organs are targets of some chemicals (17). Finally, frequencies of polymorphic genes vary by ethnic group and proportional differences in the prevalence of alleles for phase I and phase II enzymes may affect cancer risks among various populations (18). Thus several lines of evidence suggest that the evaluation of occupational causes of cancer based almost entirely on white men may not fully characterize the population burden.

The recognition of the need for more occupational studies of women led to 2 recent international conferences on this topic $(19,20)$.

\section{Spread of industrial exposures outside the workplace}

Studies of occupational groups can provide important information on cancer risks from general environmental exposures because many agents in the workplace can also occur in the general environment, although usually at much lower levels. Agents spread from the workplace by purposeful release into the air, water and soil (more so in the past than today), by accident, by inadvertent escape, and by transport to the home. This spread can lead to serious problems of environmental contamination and, 
with some compounds, increased risk for cancer. High rates of lung cancer have been associated with environmental contamination around smelters and steel plants (21) and bladder cancer with residential proximity to leather factories (22).

Mesothelioma has occurred among women whose only contact with asbestos appears to have been through their husbands' jobs (23). Studies of childhood cancer, for which associations with parental occupations are routinely reported, provides additional evidence for a possible risk from the transport of workplace chemicals to the home $(24,25)$. Studies of workers, who typically have higher exposures to most chemicals than the general public, provide a perspective on the risk from general environmental exposures.

Since many environmental exposures have counterparts in the the workplace, it seems desirable to assess cancer risks from both routes of exposure simultaneously. Although such studies are difficult from a practical point of view, there are likely to be several advantages (26). With the assessment of total exposure, studies would provide a clearer evaluation of the level of individual risk from a chemical and thus a better understanding of the public health burden. Comparing disease risks from occupational and environmental exposures should provide useful information for decision making regarding potential environmental hazards because assessing environmental exposures is extremely difficult and false negative findings are a major concern. However, if people with occupational exposures, which are usually considerably higher than environmental exposures, show no excess risk, one would be less concerned that the absence of an association with environmental exposures would simply be a false negative finding.

\section{Gene-exposure and exposure-exposure interactions}

The study of interactions between occupational and environmental carcinogens and genetic risk factors are cutting-edge issues in cancer epidemiology. Although there are many plausible interactions between known or suspected occupational carcinogens and polymorphisms in activating and detoxifying genes $(27,28)$, few have been studied to date. Molecular epidemiology studies of workers can be effectively used to identify carcinogens and to understand mechanisms of action because exposures can be clearly documented, and the timing and level of exposure can be more precisely determined than in many other exposure scenarios.

A classic example of research on gene-environment interactions is the study of the NAT2 slow acetylation phenotype and bladder cancer risk among workers exposed to aromatic amines.
It also provides some important lessons regarding such interactions. $\mathrm{N}$-acetylation of aromatic monoamines, such as 2-naphthylamine and 4-aminobiphenyl, is considered a detoxification step.

Several early papers indicated that workers exposed to aromatic amines who had the NAT2 slow acetylation phenotype were at increased risk for bladder cancer, presumably because they were less able to detoxify these compounds via $\mathrm{N}$-acetylation (29-31). Surprisingly, a study in China, conducted by Hayes and his colleagues (32), of workers exposed only to benzidine, an aromatic diamine, found that those with the slow acetylation phenotype did not have a greater risk of bladder cancer than the fast acetylators. Support for this finding has since been provided by a cross-sectional study of benzidineexposed workers. It found that the predominant DNA (deoxyribonucleic acid) adduct in exfoliated urothelial cells was acetylated (33) and confirmed that acetylation activates rather than detoxifies benzidine. This story indicates that gene-environment interactions can be highly exposure-specific and underscores the critical need for reliable and valid assessment in these investigations (34). The occupational setting often presents the opportunity for high-quality exposure assessment.

Occupational studies also offer unique opportunities to evaluate exposure-exposure interactions and effect modification. Although some of the earliest demonstrations of exposure-exposure interactions involved occupational factors (ie, between smoking and occupational exposure to asbestos) on the risk of lung cancer (35), this is not an area that has received much attention. The occurrence of multiple exposure is the human condition, and it is essential that epidemiologic investigations move beyond the traditional approach of assessment of disease risks one exposure at a time. Occupational studies with intense and well-documented exposures are particularly well situated to do this.

\section{Design recommendations}

We believe the preceding discussion documents the clear need for epidemiologic studies focusing on occupational cancer in the coming decades and illustrates the important contributions they can make to our further understanding of the causes of cancer. To maximize their potential, however, future occupational investigations can benefit from somewhat different designs than those typically employed in the past.

\section{Retrospective cohort}

The retrospective cohort has historically been the method of choice for occupational studies, and it has successfully identified many of the established chemical causes of cancer. This design has been preferred because it 
allows the assembly of large numbers of people with exposures of interest from a relatively small number of workplaces and because it provides investigators with the opportunity to visit the place of employment to obtain detailed information about exposure (36). The strength of this design has been enhanced with the improvement of exposure assessment procedures and the addition of nested case-control components which provide the opportunity to obtain information on nonoccupational factors and to collect biological tissues for the evaluation of genetic and biological markers. New approaches developed to estimate historical exposures have been discussed by others $(37,38)$ and include computer programs to assist in the storage, utilization, and documentation of the exposure assessment process (39).

Continued improvement of exposure assessment procedures and the evaluation of the reliability and validity of the various approaches employed is essential for future investigations.

One area needing work involves variation in exposure among workers holding the same job. Exposure assessment in cohort studies has usually been job-based, and within-job variation has been largely ignored. Since within-job variation may make a sizable contribution to the total variance (40), methods must be developed to include it in quantitative exposure assessments.

This development will have an impact on study design. Information on the specific approach to the job taken by individual workers is unlikely to be available in personnel records. Interviews with workers are probably required to obtain information on individual work characteristics. Nested case-control efforts would also provide the opportunity to obtain information on other risk factors to evaluate interaction, effect modification, and potential confounding (eg, potential confounding from smoking on lung cancer) (41).

The collection of biological tissues on even a small sample of subjects in cohort studies can provide extremely useful information, especially in situations in which current conditions reflect, or are informative about, past exposure circumstances. When biological samples are collected in conjunction with air monitoring, they can serve as a validation for exposure assessment procedures and provide information on within-job variation. The availability of biological tissues also allows an evaluation of the metabolic processing of toxicants and geneexposure interactions. Stored tumor tissues should be collected to provide tumor markers to stratify cases into more etiologically homogeneous subgroups, which may have stronger relationships with exposures (42).

\section{Prospective cohorts}

Many of the components recommended for retrospective cohorts can be efficiently incorporated into a prospective design. It provides opportunities for repeat contacts with participants, for the evaluation of many exposuredisease associations, and for a wide time window for the collection of biological tissues prior to the diagnosis of disease. Use of the prospective design to study cancer etiology requires direct contact with large numbers of subjects and is very expensive to establish. In the long run, however, a prospective cohort may be inexpensive in terms of the cost per amount of scientific information obtained because as time passes the cohort provides efficient and inexpensive opportunities to investigate new disease-exposure relationships.

There have been few long-term prospective cohorts established primarily for the evaluation of occupational exposures. Two prospective investigations recently initiated by the National Cancer Institute are the Agricultural Health Study and the Shanghai Women's Cohort.

The Agricultural Health Study is composed of nearly 90000 farmers and their spouses from Iowa and North Carolina and was designed to evaluate occupational, lifestyle, and genetic factors in the development of cancer and other conditions (43). It includes repeat interviews, the monitoring of pesticide exposures on a sample of participants, and the collection of biological tissues (ie, buccal cells for DNA genotyping from all participants, tumor samples for selected tumor sites, and blood and urine from a sample of healthy workers). The Shanghai Women's Cohort is a prospective study initiated by investigators at the University of South Carolina. An occupational component was added by the National Cancer Institute. This study of 75000 women from the general population can evaluate exposures associated with a number of occupations and industries. Unique aspects of this cohort include a large number of women holding production line jobs with a wide spectrum of industrial exposures. The Shanghai cohort includes repeat interviews, collection of blood and urine on all subjects, and monitoring of exposures on a sample of participants.

\section{Case-control studies}

Case-control studies have been used to evaluate occupational factors, but they have typically been perceived as inferior to retrospective cohort designs because of the low prevalence of any specific exposure and inadequate exposure assessment. Although these can be limitations, case-control studies offer advantages that are often overlooked (44). Retrospective cohorts are usually located in large industrial facilities, yet a sizable fraction of the work force is employed in small establishments. Because patterns and levels of exposure may differ between large and small companies, basing our understanding of occupational cancer on the disease experience of the largest facilities in an industry could have unintended biases. Participants in case-control studies more typically reflect a broader segment of society and avoid the large-company bias. 
Cancer diagnoses in case-control studies are likely to be more accurate than those in most retrospective cohort studies because they are usually based on medical records instead of death certificates. Concordance between diagnoses in hospital records and on death certificates varies by cancer (45), but for several cancers it is sufficiently poor to bias relative risks substantially toward the null. The reliance on interviews in case-control studies allows better control for potential confounding than cohort studies, which are typically limited to work history records.

Case-control studies nested within a cohort can be conducted, but it is difficult to locate some subjects or next-of-kin to interview because of the length of time between entry into the cohort and time of the interview. Case-control studies also provide better opportunities to assess interaction and effect modification than typically available in cohort designs because it is easier to obtain information on a wide spectrum of disease risk factors (occupation, diet, medical, life-style, and environment). This is exceedingly important if we want to characterize the burden of disease accurately across population subgroups and to integrate cancer risks from the workplace with those from other aspects of life. Finally, because of the smaller number of subjects, it is easier and less costly to obtain biological tissues for genetic and exposure analyses in case-control studies than in cohort investigations.

We believe the design of choice for occupational studies of cancer is no longer clearly tilted toward the retrospective cohort because of the need to include women and minorities, to consider the effects of, and interaction with, nonoccupational factors, and to collect biological components for genetic analyses and gene-environment interactions. Case-control and prospective cohorts may be more useful in some circumstances.

Case-control studies, however, have limitations, and methodologic investigations are needed to overcome these problems. These efforts should focus on the development of better procedures for exposure assessment, the evaluation of the potential for case-response bias, and the exploration of disease or treatment effects on biological measures of exposure.

A major improvement in the assessment of occupational exposures in case-control studies was developed by Siemiatycki and his colleagues $(46,47)$. They employed chemists to obtain detailed information on work practices and develop quantitative estimates of exposure, which provided a significant advance beyond simple analyses by occupational and industrial titles.

This approach has been modified for use in a technique employing computer-assisted interviews $(48,49)$. Procedures for developing quantitative estimates are complex, and the assessment of the reliability and validity of each step is needed. For example, assessment exposures by job or job task has been the primary approach in case-control and cohort studies. The impact of individual work habits on exposure (eg, within job variability) is a largely unchartered area. Biological monitoring suggests that the variation in exposure among persons holding the same job is as large as the variation between jobs (40), and, as with retrospective cohort studies, there is a need to develop procedures to incorporate such information into the exposure assessment procedures.

Case-response bias is a major concern in case-control studies. Although the frequency of occurrence of this bias in case-control studies is unclear (50), it is routinely voiced as a major limitation. Methodological investigations are needed to determine how often it occurs, its magnitude, and under what conditions it operates in studies of occupation and cancer. Some attempts to address this issue should be undertaken in each case-control study. For example, critical information obtained from cases and controls by interview could be compared with information from another source. In a study of pesticides, the reported use of these chemicals by farmers was compared with information from pesticide suppliers (51). Interview data could be compared with work histories from personnel records or measurement data and reported exposures could be compared with measured levels in biological tissues.

Many occupational chemicals can be monitored in blood and urine, although there is a wide range in the length of time they persist in the body. For more persistent chemicals, such as dioxin and organochlorine pesticides, the case-control approach would appear to offer an expedient design to relate disease risk to body burden. The potential utility of this approach is muted by concern over disease and treatment effects on measured levels. As with case-response bias, there is relatively little empirical information regarding this issue. Because cancer and its treatment are known to have many effects on physiological parameters, however, there is reason to believe that serum or urine levels of exposures might also be affected. Methodological studies are needed to track the pattern of measured toxicants in biological tissues prior to diagnosis, prior to treatment, and during and after cancer therapy.

\section{Cross-sectional studies}

Another study design that will be of increasing importance in the future is cross-sectional studies of healthy workers exposed to agents of concern. These studies evaluate the relationship between exposure and early markers of biological effect relevant to cancer pathogenesis. Cross-sectional studies can provide mechanistic insight into well-established carcinogens, supplement suggestive but inconclusive evidence of a chemical's carcinogenicity from epidemiologic studies of disease, and provide an initial evaluation of compounds recently introduced into the workplace (28). They can be incorporated into 
case-control studies (ie, using the controls) and into prospective and retrospective cohort studies.

Results from cross-sectional studies have already been used in the cancer evaluation process. IARC (52) concluded that there is only limited evidence for the carcinogenicity of ethylene oxide in humans after considering available annual bioassays and epidemiologic studies of cancer. Its overall evaluation, however, was that ethylene oxide is carcinogenic to humans (group 1), which was based in part upon data that ethylene oxide is associated with a dose-related increase in biomarkers of genetic damage in exposed workers (52). Studies evaluating chromosome aberrations in workers exposed to suspected DNA-damaging carcinogens will be of particular importance in the future because 3 studies have prospectively linked the chromosome aberration frequency in peripheral lymphocytes with subsequent cancer incidence or mortality (53-55).

In summary, epidemiologic studies of occupational cancer will play a vital role in the coming millennium in our effort to understand the neoplastic process. The role of occupational exposures in the development of cancer has been well documented, and their contribution to the cancer burden in the population is comparable to other carcinogenic factors, except for tobacco and diet. The basis for our understanding of occupational cancer is, however, based primarily on white men from big companies, and future studies need to include significant numbers of exposed women and minorities. The large number of leads regarding relationships between chemicals, occupations, and cancer underscore the need for future occupational investigations. Many occupational exposures may also impact the general population. Finally, investigations of occupational groups with heavy and clearly documented exposures offer unique opportunities to study interactions among genes, chemicals, and lifestyle factors, which would significantly enhance our understanding of the carcinogenic process.

\section{References}

1. Vainio H, Hemminki K, Wilbourn J. Data on the carcinogenicity of chemicals in the IARC Monographs programme. Carcinogenesis 1985;6:1653-65.

2. Doll R, Peto R. The causes of cancer. Oxford: Oxford University Press, 1981.

3. Perera FP, Boffetta P, Nisbet IC. What are the major carcinogens in the etiology of human cancer?: industrial carcinogens. Important Adv Oncol 1989:249-65.

4. Higginson J, Muir CS. Environmental carcinogenesis: misconceptions and limitations to cancer control. JNCI 1979;63:1291-8.

5. Monson R. Occupational cancer. In: Schottenfeld D, Fraumeni JF Jr, editors. Cancer epidemiology and prevention. New York (NY): Oxford University Press, 1996:373 - 405.
6. Simonato L. Workshop on priorities for epidemiologic studies on occupational cancer [report]. Scand J Work Environ Health 1987;13:74-5.

7. Blair A, Axelson O, Franklin CA, Paynter OE, Pearce N, Stevenson DE, et al. Carcinogenic effects of pesticides. In: Baker SR, Wilkinson CF, editors. The effect of pesticides on human health. Princeton (NJ): Princeton Scientific Publications, 1990:201-60.

8. International Agency for Research on Cancer (IARC). Overall evaluations of carcinogenicity: an updating of IARC monographs volumes 1 to 42 . Lyon: IARC, 1987. IARC monographs on the evaluation of the carcinogenic risks to humans, suppl 7.

9. Dich I, Zahm SH, Hanberg A, Adami HO. Pesticides and cancer. Cancer Causes Control 1997:8:420-43.

10. Zahm SH, Ward MH, Blair A. Pesticides and cancer. Occup Med 1997;12:269-89.

11. Zahm SH, Pottern LM, Lewis DR, Ward MH, White DW. Inclusion of women and minorities in occupational cancer epidemiologic research. J Occup Med 1994; 36:842-7.

12. Blair A, Zahm SH, Silverman DT. Occupational cancer among women: research status and methodologic considerations. Am J Ind Med 1999;36:6-17.

13. Silvaggio T, Mattison DR. Setting occupational health standards: toxicokinetic differences among and between men and women. J Occup Med 1994;36:849-54.

14. Zhang EA, Wynder EL. Differences in lung cancer risk between men and women: examination of the evidence. JNCI 1996;88:183-92.

15. Baldini EH, Strauss GM. Women and lung cancer: waiting to exhale. Chest $1997 ; 112: 229 \mathrm{~s}-34 \mathrm{~s}$.

16. Blair A, Hartge P, Stewart PA, McAdams M, Lubin J. Mortality and cancer incidence of aircraft maintenance workers exposed to trichloroethylene and other organic solvents and chemicals: extended follow-up. Occup Environ Med 1998;55:161-71.

17. Griesemer RA, Eustis SL. Gender differences in animal bioassays for carcinogenicity. J Occup Med 1994;36:855—9.

18. Schulte PA, Perera FP, editors. Molecular epidemiology: principles and practices. San Diego (CA): Academic Press, 1993.

19. Pottern LM, Zahm SH, Sieber SS, Schneider IJ, LaRosa JH, Brown DP, et al. Occupational cancer among women: a conference overview. J Occup Med 1994;36:809-13.

20. Gunnarsdottir HK, Kjaerheim K, Boffetta P, Rafnsson V, Zahm SH. Women's health: occupation, cancer and reproduction: a conference overview. Am J Ind Med 1999;36:1-5.

21. Brown LM, Pottern LM, Blot WJ. Lung cancer in relation to environmental pollutants emitted from industrial sources. Environ Res 1984;34:250-61.

22. Brown LM, Zahm SH, Hoover RN, Fraumeni JF Jr. High bladder cancer mortality in rural New England (United States): an etiologic study. Cancer Causes Control 1995;6:361-8.

23. Dodoli D, Del Nevo M, Fiumalbi C, laia TE, Cristaudo A, Comba $P$, et al. Environmental household exposures to asbestos and occurrence of pleural mesothelioma. Am J Ind Med 1992;21:681-7.

24. Zahm SH, Ward MH. Pesticides and childhood cancer. Environ Health Perspect 1998;106 suppl 3:893 - 908

25. Colt JS, Blair A. Parental occupational exposures and risk of childhood cancer. Environ Health Perspect 1998;106 suppl 3:909-25.

26. Blair $\mathrm{A}$, Ward $\mathrm{MH}$. The value of assessing occupational factors in epidemiologic investigations of general environmental exposures. Environmetrics 1998;9:519—24. 
27. Rothman N. Genetic susceptibility biomarkers in studies of occupational and environmental cancer: methodologic issues. Toxicol Lett 1995;77:221-5.

28. Rothman N, Hayes RB. Using biomarkers of genetic susceptibility to enhance the study of cancer etiology. Environ Health Perspect 1995;103 suppl 8:291-5.

29. Cartwright RA, Rogers HJ, Barham-Hall D, Glashan RW, Ahmad RA, Higgins E, et al. Role of $\mathrm{N}$-acetyltransferase phenotypes in bladder carcinogenesis: a pharmacogenetic epidemiological approach to bladder cancer. Lancet 1982;2:842-6.

30. Hein DW. Acetylator genotype and arylamine-inducted carcinogenesis. Biochem Biophys Acta 1988;948:37-66.

31. Hanke J, Krajewska B. Acetylation phenotypes and bladder cancer. J Occup Med 1990;32:917-8.

32. Hayes RB, Bi W, Rothman N, Braille F, Caporaso N, Feng P, et al. N-acetylation phenotype and genotype and risk of bladder cancer in benzidine-exposed workers. Carcinogenesis 1993;14:675-8.

33. Rothman N, Bhatnagar VK, Hayes RB, Zenser TV, Kashyap SK, Butler MA, et al. The impact of interindividual variation in NAT2 activity on benzidine urinary metabolites and urothelial DNA adducts in exposed workers. Proc Natl Acad Sci USA 1996;93:5084-9.

34. Rothman N, Garcia-Closas M, Stewart W, J, Lubin J. Impact of misclassification in studies of gene-environment interactions. In: Boffetta P, Caporaso N, Cuzick J, Lang M, Vineis P, editors. Metabolic polymorphisms and cancer. Lyon: IARC. In press.

35. Blot WJ, Fraumeni JF Jr. Cancers of the lung and pleura. In: Schottenfeld D, Fraumeni JF Jr, editors). Cancer epidemiology and prevention. New York (NY): Oxford University Press, 1996:637-5.

36. Blair A, Hayes RB, Stewart PA, Zahm SH. Occupational epidemiologic study design and application. In: Bang KM, editor. Occupational epidemiology. Philadelphia (PA): Hanley and Belfus Inc, 1996:403-19. Occupational medicine: state of the art reviews, vol 11.

37. Checkoway H, Dement JM, Fowler DP, Harris RL, Lamm $\mathrm{SH}$, Smith TJ. Industrial hygiene involvement in occupational epidemiology. Am Ind Hyg Assoc J 1987;48:515-23.

38. Stewart PA, Lees PSJ, Francis M. Quantification of historical exposures in occupational cohort studies [review]. Scand J Work Environ Health 1996;22:405-14.

39. Stewart PA, Triolo H, Zey J, White D, Herrick RF, Hornung $\mathrm{R}$, et al. Exposure assessment for a study of workers exposed to acrylonitrile, II: a computerized exposure assessment program. Appl Occup Environ Hyg 1995; 10:698-706.

40. Rappaport SM. Selection of measures of exposure for epidemiologic studies. Appl Occup Environ Hyg 1991;6:448-57.
41. Blair A, Stewart PA, Zaebst DD, Pottern L, Zey JN, Bloom $\mathrm{TF}$, et al. Mortality study of industrial workers exposed to acrylonitrile. Scand J Work Environ Health 1998;24 suppl 2:25-41.

42. Taylor JA, Sandler DP, Bloomfield CD, Shore DL, Ball ED, Neubauer A, et al. Ras oncogene activation and occupational exposures in acute myeloid leukemia. JNCI 1992;84:162632.

43. Alavanja MC, Sandler DP, McMaster SB, Zahm SH, McDonnell $\mathrm{CJ}$, Lynch CF, et al. The agricultural health study. Environ Health Perspect 1996;104:362 -9.

44. Siemiatycki J. Risk factors for cancer in the workplace. Boca Raton (FL): CRC Press, 1991.

45. Percy C, Stanek E, Gloeckler L. Accuracy of cancer death certificates and its effect on cancer mortality statistics. Am J Public Health 1981;71:242-50.

46. Siemiatycki J, Day N, Fabry J, Cooper JA. Discovering carcinogens in the occupational environment: a novel epidemiologic approach. JNCI 1981;66:217-25.

47. Gerin M, Siemiatycki J, Kemper H, begin D. Obtaining occupational exposure histories in epidemiologic case-control studies. J Occup Med 1985;27:420-6.

48. Stewart WF, Stewart PA. Occupational case-control studies, I: collecting information on work histories and work-related exposures. Am J Ind Med 1994;26:297-312.

49. Stewart PA, Stewart WF. Occupational case-control studies, II: recommendations for exposure assessment. Am J Ind Med 1994;26:313-26.

50. Coughlin SS. Recall bias in epidemiologic studies. J Clin Epidemiol 1990;43:87-91.

51. Blair A, Zahm SH. Patterns of pesticide use among farmers: implications for epidemiologic research. Epidemiology 1993:4:55-62.

52. International Agency for Research on Cancer (IARC). Some industrial chemicals. Lyon: IARC, 1994. IARC monographs on the evaluation of carcinogenic risks to humans, vol 60 .

53. Hagmar L, Brogger A, Hansteen I-L, Heim S, Högstedt B, Knudsen L, et al. Cancer risk in humans predicted by increased levels of chromosomal aberrations in lymphocytes: Nordic study group on the health risk of chromosome damage. Cancer Res 1994;54:2919-22.

54. Bonassi S, Abbonddandolo A, Camurri L, Pra LD, Ferrari $\mathrm{MD}$, Degrassi $\mathrm{F}$, et al. Are chromosome aberrations in circulating lymphocytes predictive of future cancer onset in humans?: preliminary results of an Italian cohort study. Cancer Genet Cytogenet 1995;79:133-5.

55. Liou S H, Lung J-C, Chen Y-H, Yang T, Hsieh L-L, Chen C$\mathrm{J}$, et al. Increased chromosome-type chromosome aberration frequencies as biomarkers of cancer risk in a blackfoot endemic area. Cancer Res 1999;59:1481-4. 